\title{
Modernização e industrialização em contexto colonial: a exploração petrolífera em Angola (1965-1974)
}

\section{Leonardo Aboim Pires}

Anvestigador no Instituto de História Contemporânea da Faculdade de Ciências Sociais e Humanas da Universidade Nova de Lisboa. Lisboa [Lisboa] Portugal <leonardopires5@hotmail.com>.

\section{Resumo}

No período do pós-guerra, o Estado Novo promoveu o desenvolvimento económico das províncias ultramarinas e durante a década de 1960, Angola tornar-se-á no caso paradigmático do valor económico das colónias e do investimento governamental nas infraestruturas industriais. Este artigo pretende aprofundar o estudo de um sector específico - a indústria petrolífera - no contexto da relação entre as elites económicas e o governo metropolitano, na conjuntura política do período final da ditadura, sobretudo tendo presente os movimentos de resistência e a guerra colonial, mas ainda da perceção da crise petrolífera de 1973 e as suas consequências.

\section{Palavras-chave}

Desenvolvimento industrial. Indústria petrolífera. Colonialismo português.

\section{Modernization and industrialization in colonial context: the oil exploration in Angola (1965-1974)}

\begin{abstract}
During the post-war, the Estado Novo conducted the economic development of the overseas provinces and during the 1960's Angola became a paradigmatic example of the economic value of the colonies and the government's investment in industrial infrastructures. With this article it is intended to contribute to deepen the study of a particular sector - the oil industry - in the relations between the local economic elites and the metropolitan government in the political situation of the final period of the dictatorship, especially bearing in mind the resistance movements and the colonial war, and still of the perception of the 1973 oil crisis and its consequences.
\end{abstract}

\section{Keywords}

Industrial development. Oil industry. Portuguese colonialism. 


\section{Introdução}

Enquadrando a análise da história da indústria petrolífera portuguesa numa visão sistémica das políticas de desenvolvimento económico colonial durante o Estado Novo, o presente ensaio ${ }^{1}$ pretende analisar a emergência da exploração deste sector no território angolano nos anos finais da administração colonial portuguesa. É importante salientar que as políticas energéticas do Estado Novo, e em específico sobre o petróleo, é uma situação a que a historiografia pouco alude, embora com algumas recentes exceções (Veiga, 1999, pp. 50-57; Silva, 2015, pp. 179-186).

As condições naturais do território angolano revelaram-se propícias à prospeção petrolífera, facto que suscitou a atenção de interesses internacionais, desde belgas a norte-americanos, sendo possível ler esta abertura à iniciativa privada como um sinal da internacionalização da economia portuguesa que se foi operando desde a década de 1950. Este será outros temas tratados na investigação que se segue.

Numa conjuntura particularmente marcada pela luta armada dos movimentos de libertação, o pensamento político das elites brancas angolanas repercutia-se, de forma óbvia, na modelação das políticas e estruturas económicas, a que o petróleo não estava alheio, devido ao enorme peso que foi ganhando na balança comercial angolana. Assim, e partindo da análise de Fernando Tavares Pimenta, a reação das elites brancas angolanas face ao processo de industrialização será outros dos vértices temáticos das páginas que se seguem.

As consequências da crise petrolífera ocorrida a partir de Outubro de 1973 também serão objeto de análise deste ensaio, onde se tentará perspetivar quais os impactos, a nível económico angolano, bem como a nível político nacional, onde as questões sobre a política energética serão analisadas, mas igualmente os impactos a nível do quotidiano da população da província.

\section{A modernização económica de Angola do pós-guerra à queda do regime}

O clima económico mundial do pós-guerra caracterizou-se pelo mais longo período de crescimento do século XX, onde o pleno emprego era uma das suas bases, não se fazendo sentir recessões, nem flutuações cíclicas. Além destas características, "a Europa Ocidental, nomeadamente, experimentou estabilidade no plano politico e social, uma elevação do nível de vida e atingiu níveis superiores do consumo" (Veiga, 1999, p. 51). A realidade portuguesa do pós II Guerra Mundial intentou um surto industrializante, embora matizado pelas contrariedades impostas pela estrutura económica de base corporativa e onde se fazia sentir um forte dirigismo estatal, a que se deve somar a opção pelo investimento do sector primário. Contudo, esta situação foi sendo reconfigurada, sobretudo a partir da segunda metade da década de 1950, assistindo-se a uma progressiva redefinição das prioridades económicas, onde os preceitos autárcicos foram dando lugar a uma internacionalização da economia portuguesa e a sua inserção nos movimentos de cooperação europeia, onde o espaço ultramarino não ficou alheio a este movimento, onde Angola se converte num exemplo paradigmático.

Entre os mecanismos encontrados pelo governo salazarista para o desenvolvimento do país um deles foi a economia planificada, através dos planos de fomento. Assim, o I e o II Planos de Fomento (1953-1958 e 1959-1964) apostaram, de forma determinante, no planeamento e construção de infraestruturas rodoviárias, portuárias, aeroportuárias e ferroviárias no território angolano, tendo em vista a reconversão de atividades, sobretudo a nível industrial, sobretudo na indústria mineira, perspetivando ainda a fixação de colonos oriundos da metrópole, para o povoamento de algumas regiões. 0 aproveitamento dos recursos naturais de Angola converteu-se na pedra de toque da política economia dos anos seguintes, tenha sido na década de 1960 que estas intenções se materializaram na reconversão e construção de estruturas como caminhos-de-ferros ou portos.

\footnotetext{
1 Este ensaio parte da investigação desenvolvida no âmbito do seminário «Ciclo Africano do Império: Colonialismo, Guerra e Descolonização no Portugal Contemporâneo», do Mestrado em História Contemporânea da FCSH/UNL. A investigação beneficiou-se das discussões sobre o tema e o interesse demonstrado pelo Professor Doutor Pedro Aires Oliveira, a quem deixamos o nosso agradecimento. Ao Professor Doutor Fernando Tavares Pimenta igualmente agradecemos pelas úteis indicações bibliográficas dadas para esta investigação.
} 
Deste modo, nas palavras de José Gonçalo Correia d'Oliveira, "para contrabalançar as forças externas de atração exercidas ao mesmo tempo em África e na Europa, só muito poucos e sem dúvida menos esclarecidos defenderam uma solução de ensimesmamento nacional" 2 , mostrando que a internacionalização económica de Portugal e das províncias ultramarinas era a solução adequada às exigências coetâneas.

Já no que é relativo à realidade angolana, Rogério Martins, um dos paladinos da industrialização do marcelismo, declarou que "a indústria é assim o grande modo de promover, sustentar e acelerar o desenvolvimento económico e social"3, denotando-se que, efetivamente, foi a industrialização que promoveu um "milagre económico" deste território, alcançando níveis de desenvolvimento inauditos durante as décadas de 1960 e 1970. Como menciona Ana Maria Neto, o desenvolvimento económico que se verificou neste período "colocou Angola numa posição ímpar no conjunto dos países da África intertropical e levou a apontá-la como exemplo no plano mundial, a par do do Japão" (Neto, 1990, p. 9). Apesar do inegável desenvolvimento que o sector secundário sofreu nos anos finais da administração portuguesa durante o recorte cronológico atrás referido, Angola tinha uma economia que assentava, sobretudo, no sector agrícola onde o café, a cana-de-açúcar, o sisal, o milho, o óleo de coco, o amendoim, o algodão, o tabaco e a borracha se destacavam como as principais culturas agrícolas deste período. Deste modo, o investimento económico também se fez sentir na agricultura, onde se denota um incremento, no que concerne às exportações, até meados da década de 1970.

Tabela 1. Exportação das principais culturas agrícolas de Angola (toneladas).

\begin{tabular}{|c|c|c|c|c|}
\hline Culturas & $\mathbf{1 9 6 0}$ & $\mathbf{1 9 6 5}$ & $\mathbf{1 9 7 0}$ & $\mathbf{1 9 7 2}$ \\
\hline Café em grão & 87.217 & 159.168 & 180.554 & 176.855 \\
\hline Sisal & 58.571 & 50.345 & 65.862 & 66.501 \\
\hline Milho & 117.111 & 168.199 & 171.393 & 76.665 \\
\hline
\end{tabular}

Fonte: OLIVEIRA, 1985, p. 95

Em Maio de 1962, o presidente da Associação Industrial de Angola, António Garcia de Castilho alertava para a necessidade da internacionalização da económica ultramarina nos seguintes termos: "[...] para alguns dos nossos industriais, chegou a hora de uma angustiante alternativa: ou fabricam tão bom e tão apresentado como a Metrópole e o estrangeiro e a preços de concorrência, ou terão os seus dias contados" 4 . Associada a este esforço no sentido da modernização económica, acentuava-se outra faceta desta realidade: a integração do mercado colonial na economia nacional, algo já vinha sendo trabalhado, desde 1961, com a criação do Espaço Económico Português, sob a égide de José Gonçalo Correia d'Oliveira. Este é um intento no qual certas figuras apostam e defendem, tal como Augusto Sá Viana Rebelo 5 , que afirma que devido às "potenciais matérias-primas dos territórios do espaço português, e a eles acrescermos os potenciais energéticos naturais existentes nos mesmos territórios [...] poderemos retirar como ilação imediata que nenhum país do Mundo [...] tem as possibilidades económicas de Portugal"6.

A consciencialização das elites económicas angolanas da encruzilhada económica em que se encontravam leva a que o governo metropolitano tome medidas legislativas no sentido de reforçar o investimento colonial. Através do quadro exposto, não é de estranhar que a 24 de Novembro de 1965, fosse promulgado o Decreto-Lei no 46.666, que revogou a lei do condicionamento industrial de

2 Jornal de Benguela, no 4678, 5 de Abril de 1971, p. 2.

3 Boletim da Associação Industrial de Angola, ano XXI, no 84 (1970), p. 6.

4 Boletim da Associação Industrial de Angola, ano XX, nº 77, 1968, p. 115.

${ }^{5}$ Advogado de formação, foi Presidente da Direcção do Grémio dos Industriais de Lanifícios do Sul, Vogal do Conselho Técnico da Indústria e do Conselho Administrativo do Instituto Nacional de Investigação Industrial e procurador à Câmara Corporativa (1965-1974).

6 Boletim da Associação Industrial de Angola, ano XIX, no 73/74, 1967/1968, p. 25. 
1936. Este facto é, na opinião de Fernando Tavares Pimenta, resultado de uma concessão do governo de Lisboa face às pressões das elites coloniais brancas, no sentido de desenvolvimento económico e industrial do território angolano (Pimenta, 2008, p. 310). Este decreto destacava a necessidade, como refere Rui Santos Martins, "da criação de um vasto mercado pela supressão progressivas de entraves aduaneiros e de outra natureza que existem nas relações entre as várias parcelas do território nacional"7, algo que já era previsto no artigo 4ํ do Decreto-Lei no 44.016, de 8 de Novembro de 1961, que lançou as bases do Espaço Económico Português. No quadro de renovação da economia colonial, dever-se-á acrescentar que devido ao facto de que "a rápida expansão da vida económica das províncias ultramarinas tem revelado insuficiências na atuação dos serviços provinciais da economia"8, o decreto-lei no 47.638, de 22 de Abril de 1967, procede à reorganização do serviços económicos do Ultramar, sendo outra importante peça legislativa que promove a integração económica do espaço ultramarino português.

\subsection{0 fator africano nas relações económicas luso-brasileiras}

Um aspeto a que, quer o governo provincial, quer o governo metropolitano, deram atenção foi a possibilidade de Angola se tornar num importante parceiro nas relações económicas luso-brasileiras. É nos finais da década de 1960 que a diplomacia económica entre Portugal e Brasil se estreita, patente no Acordo de Comércio, assinado em Setembro de 1966, facto que mostrava que "os alicerces de uma ação de grande amplitude, associando atividades industriais de Portugal e do Brasil em positivas realizações de interesse comum, foram firmemente lançados" 9 . A conjuntura política brasileira, depois do golpe de 1964 e a consequente instauração de uma ditadura militar, foi propícia a que o desenvolvimento interno, sobretudo a nível industrial, encarasse as relações com Portugal numa perspetiva renovada. Esta situação não estava desligada do contexto de conflito armado que se vivia nas colónias portuguesas, onde "a forceful Brazilian role in Africa will also satisfy her desire to preserve Portuguese culture in Africa and expand her eastern frontier, which now extends to West Africa" (Glasgow, 1972, p. 8). A vitória dos movimentos de libertação contribuiria para o desequilíbrio de forças em África, possibilitando uma maior penetração da influência soviética na região, algo a que o governo brasileiro estava disposto a combater pois "o Brasil vê nas províncias ultramarinas uma continuação do território português"10.

A aproximação entre portugueses e brasileiros resultava, nas palavras do economista brasileiro José Garrido Torres, que "entre Brasil, Portugal e Províncias Ultramarinas, existe uma identidade natural, que nos une e que resulta de sermos essencialmente a mesma gente", mas, à época denotava-se que "falta, por outro lado, uma infraestrutura económica que sirva de base operativa àquela Comunidade"11. Essa seria uma opinião partilhada pela elite governativa coeva, adepta da teoria de que, a similitude linguística, social e económica entre Brasil, Portugal e os territórios africanos era potenciadora de uma relação que deveria ser mais estreita e com efeitos recíprocos. Assim, Jorge Eduardo da Costa Oliveira mostrava, numa entrevista dada ao jornal brasileiro $O$ Globo, que "Angola precisa do apoio do Brasil para acelerar o seu desenvolvimento agrícola e industrial, e o maior benefício que poderá resultar de nossos contactos aqui se relaciona com o aproveitamento do know-how brasileiro em muitos domínios" (Oliveira, 1972, p. 657).

A presença comercial do Brasil em Angola repercutiu-se em diversos sectores económicos ${ }^{12}$. 0 sector agropecuário foi um dos visados, onde a adaptabilidade do gado brasileiro ao solo angolano só foi possível depois do investimento do governo provincial no envio de missões científicas de estudo ao Brasil. Contudo, a nível do sector agrícola, as relações bilaterais entre Angola e Brasil

\footnotetext{
7 Boletim da Associação Industrial de Angola, ano XIX, nª 73/74, 1967/1968, p. 77.

8 Boletim da Associação Industrial de Angola, ano XVIII, № 71, 1967, p. 100.

9 Indústria Portuguesa, ano 39, nº460, Junho de 1966, p.261.

10 Jornal de Benguela, $\mathrm{n}$ ⒋464, 31 de Janeiro de 1972, p. 1.

11 Indústria Portuguesa, ano 41, no 489, Novembro de 1968, p.685.

12 Cf. Jornal de Benguela, no 4666, 22 de Fevereiro de 1971, p. 6; no 4667, 25 de Fevereiro de 1971 - p. 1; no 4680, 12 de Abril de 1971, p. 1 e n⿳04724, 13 de Setembro de 1971, p. 1.
} 
eram de difícil operacionalização, uma vez que as duas economias eram muito semelhantes, o que potenciava uma competitividade, e não uma aproximação. Ainda assim, e devido ao facto de que este "sector tradicional destina-se quase apenas às necessidades de autoconsumo" (Guerra, 1979, p. 69), um investimento nesta área conservava a possibilidade de um aumento dos réditos das exportações.

Todavia, no sector industrial, as parcerias comerciais revelavam-se com uma maior facilidade. Como Jorge Eduardo Costa Oliveira referiu, "no domínio puramente industrial, é de admitir que os industriais brasileiros estejam dispostos a colaborar connosco no desenvolvimento de Angola, em sectores que eles já bem conhecem"13, sobretudo o sector têxtil e dos eletrodomésticos. Dentro da indústria, o petróleo foi, igualmente, foco da atenção brasileira pois acentuava-se o investimento deste governo no sector energético e, especificamente, na indústria petrolífera. Assim, em meados da década de 1970, a companhia Petrobrás começou a realizar investimento em África, primeiramente na Nigéria, mas estendendo-se aos territórios de Angola e Moçambique. Contudo, a atuação efetiva da Petrobrás em Angola só seria conseguida em 1979, já depois da independência.

Em suma, o que se verifica entre 1961 e 1971 é o que Nuno Valério e Paula Fontoura denominaram como um "período liberal" (Valério \& Fontoura, 1994, p. 1202), na medida em que os tradicionais entraves ao comércio colonial foram sendo sucessivamente levantados, onde o Espaço Económico Português foi o passo mais decisivo numa nova relação entre a metrópole e as colónias, a nível monetário, financeiro e mercantil. Os elevados índices de crescimento eram, na opinião de Francisco Costa Gomes, "a melhor resposta à propaganda que se empenha obstinadamente em diminuirnos perante o mundo" 14 , numa clara aposta em "conquistar os corações e as mentes" (Smith, 1990, p. 223) através do desenvolvimento económico, como constata Gervase Clarence-Smith.

\section{Os anos iniciais da exploração de petróleo em Angola (1954-1965)}

A procura de novas fontes de energia levou as indústrias a focar a sua atenção no petróleo. Em meados dos anos 50, "quase metade da energia total consumida no mundo provém do petróleo e do gás natural que com ele é encontrado" (A Indústria do Petróleo, 1955, p. 9), criando um ambiente que poderia ser denominado como a "fome de energia" 15.

As condições geográficas do território angolano revelavam-se particularmente propícias para a exploração de recursos naturais como petróleo, diamantes ou exploração mineira. A este quadro natural, dever-se-á associar o desenvolvimento tecnológico e científico que desponta ao longo da década de 1950, que possibilitou estudos e análises no sentido de aumentar a capacidade de extração nas operações produtivas, situação igualmente resultante de um conhecimento empírico cada vez mais sustentado, oriundo da construção da refinaria de Cabo Ruivo, inaugurada em 1940 e, à época, o maior projeto industrial do Estado Novo.

No que toca especificamente ao território provincial de Angola, a primeira tentativa de prospeção petrolífera ficou realizada pela Companhia de Combustível do Lobito, em 1952. Embora a ausência de um plano sistemático por parte dos governos metropolitano e provincial para a exploração deste recurso mineral, acabou por dirimir o impacto da exploração petrolífera no Lobito. Mas será em 1954 que se dá a descoberta de petróleo em Benfica, na bacia do rio Cuanza16, iniciandose a sua exploração sob os auspícios do grupo belga Petrofina. A esta descoberta, seguiram-se outras em Cacuaco, Tobias, Luanda e Cabinda, sendo uma "atividade promissora para os interesses nacionais"17. Em Dezembro de 1955, o Ministro do Ultramar autorizou a instalação de uma refinaria em Luanda, com uma capacidade de produção que variava entre 500.000 a 1.000 .000 toneladas por ano e, posteriormente, a o governo-geral de Angola cria uma pareceria com a

\footnotetext{
13 A Província de Angola, 29 de Setembro de 1972, p. 1.

14 A Província de Angola, no 14.659, 23 de Maio de 1971, p. 8

15 Jornal de Benguela, no 4864, 18 de Janeiro de 1973, p. 1.

16 Boletim Geral do Ultramar, vol. XXXI, no 358, 1955, p. 287.

17 A Província de Angola, no 14.665, 29 de Maio de 1971, p. 26.
}

(c) Labor \& Engenho, Campinas [SP] Brasil, v.11, n.4, p.507-519, out./dez. 2017. 
Petrofina, criando, em 1957 uma nova companhia petrolífera, a Petrangol, mais tarde associada à Angol. 0 paulatino desenvolvimento da atividade petrolífera leva a que começasse a ser tributada, por parte do governo provincial, situação regulada pelos decretos no 41.356 e 41.357, de 11 de Novembro de 1957.

As capacidades do desenvolvimento da indústria petrolífera no arranque da economia provincial foram reconhecidos pelo governo, que poderia, num curto espaço de tempo potenciar "uma autêntica revolução na Economia da Província" (Oliveira, 1972, p. 574). 0 germinar deste sector industrial levou a que as exportações de petróleo contribuíssem, de forma significativa, para o equilíbrio da balança comercial angolana. Deste modo, enquanto, em 1960, a exportação dos derivados de petróleo (gás butano, gasolina de aviação, gasolina, gasóleo, fuel e jet-fuel), ascendia a 139.450 toneladas, em 1964, estes valores seriam de 305.100 toneladas. Apesar do desenvolvimento de outros sectores, nenhum outro contribui, de forma tão evidente para o chamado "milagre económico angolano", com repercussões ao nível das exportações, investimento de capital e tributações fiscais e aduaneiras.

A importância da iniciativa privada no desenvolvimento económico da colónia é reconhecido pelo governo provincial que, nas palavras do antigo Governador-Geral de Angola, Horácio Sá Viana Rebelo, "muito deve Angola às empresas privadas, e o seu apoio e a sua ação têm sido alavancas para a prosperidade da Província"18. Esta iniciativa privada era, sobretudo, oriunda de outros países, como os EUA, a Bélgica ou a França, onde a concessão de benefícios fiscais foi uma das formas que o governo provincial encontrou para a fixação de investimento estrangeiro em Angola. Esta era uma situação que o governo português incentivava, sensivelmente desde 1962, para fazer face aos problemas do esforço bélico em África, intensificando-se depois de 1968. A presença de estrangeiros na reestruturação económica de Angola encontrava eco em diversos domínios, como a exportação de know-how, onde o conhecimento e assistência técnica ou os métodos de gestão e comercialização passavam pela contratação de técnicos estrangeiros, como reconhecia Rogério Martins ${ }^{19}$. Esta é uma situação a que as elites brancas estarão atentas, mostrando que a formação de mão-de-obra qualificada, desde o operariado até à aos técnicos "traria ao contexto socioeconómico de Angola um contributo que poderia ser valioso"20.

\section{0 “boom” da exploração petrolífera (1965-1973)}

Após a Guerra dos Seis Dias e as suas consequências para o mercado do petróleo, o governo encetou a realização considerável número de contratos de prospeção e exploração em diferentes regiões de Angola. Em 1967, é assinado um contrato entre o governo provincial de Angola e a Cabinda Gulf Oil Company para a concessão de pesquisas e exploração de jazigos petrolíferos no golfo de Cabinda. Entre as obrigações da companhia salientava-se "preparar [...] um programa para desenvolvimento rápido dos campos petrolíferos, instalação dos meios necessários de produção, transporte por oleoduto e exportação, com fim de colocar a área em produção o mais rapidamente possível". Por sua vez, as autoridades portuguesas deveriam autorizar em "harmonia com as leis e regulamentos em vigor, a construção instalação e uso [...] de quaisquer edifícios e instalações industriais [...]" e ainda "o uso e acesso livre de terrenos públicos secos ou submersos, situados na área de concessão"21. Este contrato é sintomático da relação recíproca entre as autoridades provinciais angolanas e o investimento estrangeiro em Angola, onde, em 1969, seria celebrado um novo acordo, onde foram introduzidas as normas da OPEP para efeitos tributários. Além das quatro companhias que procediam à prospeção de petróleo (PETRANGOL, ANGOL, CABGOC, TEXACO), nos finais da década de 1960, encontravam-se pendentes "cerca de duas dezenas de pedidos para as bacias sedimentares de Benguela e Moçâmedes" (Oliveira, 1972, p. 21).

\footnotetext{
18 Boletim da Associação Industrial de Angola, ano XVIII, no 72, 1967, p. 63.

${ }^{19}$ A Província de Angola, no 14881, 8 de Janeiro de 1972, p. 5

20 Jornal de Benguela, no 4801, 8 de Junho de 1972, pp. 1-3

21 Contrato entre a província de Angola e a Cabinda Gulf Oil Company (Cabgoc) para a concessão, em regime de exclusivo, de pesquisas e exploração de jazigos de hidrocarbonetos sólidos, líquidos e gasosos naquela província. Lisboa: Ministério do Ultramar, 1967, pp. 6-8.
} 


\subsection{0 marcelismo e a economia angolana}

A nomeação de Marcello Caetano como Presidente do Conselho de Ministros, em Setembro de 1968, apesar da aura reformista que lhe estava associada, não operou mudanças significativas a nível da política ultramarina, uma vez que a abertura política entendia-se no quadro do regime vigente. Assim, no seu primeiro discurso ao país, a 27 de Setembro, mostrava o seu "compromisso da fidelidade à doutrina salazarista; da continuação intransigente da defesa das províncias ultramarinas; o da luta contra o comunismo". Assim, "sendo a sua opção pela manutenção desta, assumiu perante a política colonial um compromisso de continuidade" (Souto, 2007, p. 42). Todavia, Marcello Caetano mostrava aceitar "a independência das duas colónias de povoamento português, Angola e Moçambique" (Pimenta, 2008, p. 315), mas onde os colonos brancos seriam os protagonistas destes territórios na eventualidade da concessão de independência, e não os líderes dos movimentos independentistas.

Apesar do quadro anteriormente descrito, o governo marcelista possibilitou uma paulatina mutação na forma como as colónias eram vistas, do ângulo económico. Durante o consulado marcelista, assiste-se a "um grau de flexibilidade que abria consideráveis perspetivas à relação de Portugal com a África sob a sua bandeira como à relação de Portugal com os aliados do Ocidente" (Antunes, 1990, p. 81). Embora, nos relatos diplomáticos britânicos coevos, a política económica que seria seguida por Caetano mostrava que seria ditada "by necessity rather than choice; but nevertheless the economy of Portugal will have to come under close scrutiny before long". Todavia, acrescentava-se que "this is by no means to suggest that her African policy in itself will be changed overnight"22.

A conjugação de um novo olhar económico sobre o país, associado à internacionalização da economia portuguesa, iniciada com a adesão à EFTA, em 1960, confluiu num maior investimento de capitais estrangeiros nas colónias, onde o sector industrial beneficiou, de forma clara, deste novo quadro. Em suma, e como refere Fernanda Rollo, com o Marcelismo "[...] os novos termos em que se punha o prosseguimento da modernização da economia e indústria portuguesas, foram efetivamente [...] alterados" (Rollo, 2007, p. 128). Assim, a tentativa de superação das clivagens sistémicas da economia e a mutação nas diretrizes da política industrial que o governo marcelista introduziu teve evidentes repercussões no contexto colonial.

O impacto da exploração do petróleo revelou-se significativo no equilíbrio da balança comercial de Angola, fazendo jus às vozes das elites que defendiam que "haverá que iniciar-se uma etapa de exploração e busca de petróleo sem precedentes no Mundo inteiro e de inversões astronómicas que hão-de atingir montantes incríveis"23. Entre 1968 e 1971, ocorreu um abrandamento das importações, devido, sobretudo à "compra de bens de equipamento [...] em virtude do apetrechamento maciço dos dois principais projetos industriais da Província (minérios de ferro e petróleo)"24. Este crescimento exponencial da prospeção petrolífera repercute-se nos meios diplomáticos, onde a diplomacia britânica constatava que, em 1968, "in the African provinces the economic prospects are bright, especially since the important oil strike in September of the Cabinda Enclave", embora as actividades económicas "have been overshadowed by the presence of terroristic activities"25. Importa salientar que em Novembro de 1971, a publicação do DecretoLei n.. $478 / 71$, o governo tentou solucionar o chamado "problema das transferências", para que o desenvolvimento angolano se fizesse sentir nos restantes territórios no "espaço económico português".

Através do III Plano de Fomento (1968-1973), o governo de Marcello Caetano, interessado em impulsionar novos empreendimentos industriais, não descurou a área da energia, sendo este renovado interesse na industrialização do país que possibilitou a realização de estudos, no sentido de construir, em Sines, uma nova refinaria, a que, posteriormente, se deveria criar uma ligação a

\footnotetext{
22 Public Record Office - Foreign Office, doc. 9-967, 20 de Dezembro de 1968.

23 Jornal de Benguela, no6669, 4 de Março de 1971, p. 1.

${ }^{24}$ Boletim da Associação Industrial de Angola, ano XX, no 78, 1968-1969, p. 115.

25 Public Record Office - Foreign Office, doc. 9-352, 11 de Janeiro de 1968.
}

(c) Labor \& Engenho, Campinas [SP] Brasil, v.11, n.4, p.507-519, out./dez. 2017. 
um complexo petroquímico baseado no sistema de steam cracking (Vaz, 2002, p. 317). Como recorda António Martins, primeiro diretor do Gabinete da Área de Sines, "na data em que se começou, tudo foi feito de acordo com o melhor state of art dessa época" (Martins, 2002), sintomático do interesse que o sector secundário despoletava entre a elite governativa, na senda do reforço da inovação técnica. A diplomacia britânica, mais uma vez atenta ao desenrolar do desenvolvimento económico, mostrava que a década de 1970 inaugurava-se sob o signo de um "real progress towards bringing a number of major projects, which in 1970 were still in the discussion stage, towards realisation" 26 .

Mas também em Angola se fazia sentir investimento na inovação e modernização tecnológica, de que é exemplo a ampliação da refinaria de Luanda, em 1971, onde "pela primeira vez uma firma portuguesa de engeenring foi escolhida pela indústria do petróleo para empreiteira principal de uma obra de grande envergadura" 27 . Mas esta obra era igualmente sintomática de que "marca, pois, aspetos significativos que importa salientar como sejam: subordinação à política governamental de máxima participação nacional [...] o importante papel das firmas nacionais de engineering na realização desta política; a existência de firmas portuguesas capazes de centralizar a realização de unidades industriais de vulto", onde se denota uma crítica implícita à excessiva dependência e ingerência dos interesses estrangeiros no desenvolvimento económico de Angola.

É também no III Plano de Fomento que o investimento para Angola é reforçado, tendo como principais objetivos "a intensificação do aproveitamento dos recursos do subsolo; melhoria do nível de produção e produtividade do sector agropecuário; aumento e valorização da produção piscatória; desenvolvimento paralelo do processo de industrialização; complemento e ampliação da rede de infraestruturas; promoção a ritmo cada vez mais acelerado das populações" (Oliveira, 1972, pp. 94-95). Este conjunto de iniciativas enquadra-se num plano global de desenvolvimento da província, como foi referido anteriormente. Já o investimento calculado para a indústria dos derivados do petróleo em Angola atingia o valor de 300.000 contos, a terceira maior parcela dos investimentos previstos para o território, precedido pela indústria metalúrgica de base $(1.390 .000$ contos) e pela indústria de alimentação, com exceção do sector das bebidas (956.000 contos) 28 .

Tabela 2. Produção de petróleo em Angola.

\begin{tabular}{|c|c|}
\hline Ano & Toneladas \\
\hline 1964 & 904.757 \\
\hline 1965 & 655.365 \\
\hline 1966 & 631.319 \\
\hline 1967 & 587.152 \\
\hline 1968 & 749.154 \\
\hline 1969 & 2.457 .512 \\
\hline 1970 & 5.065 .105 \\
\hline 1971 & 5.721 .400 \\
\hline 1972 & 7.057 .253 \\
\hline 1973 & 8.175 .201 \\
\hline
\end{tabular}

Fonte: Anuário Estatístico de Portugal: Ultramar (1964-73).

\footnotetext{
26 Public Record Office - Foreign Office, doc. 9-1578, Janeiro de 1971.

27 Jornal de Benguela, no 4675, 25 de Março de 1971, p. 1.

28 Boletim da Associação Industrial de Angola, ano XVIII, no 72, 1967, p. 89.
} 


\subsection{A reação das elites brancas}

Contudo, a expansão económica motivada pela exploração dos jazigos petrolíferos não foi isenta de tensões entre as elites locais e o governo metropolitana, numa época em que o futuro administrativo das províncias ultramarinas era debatido. A situação, nos inícios da década de 1970, caraterizava-se por "all dealings with the government on major contract and policy questions are conducted in Lisbon between the Overseas Ministry and the company's small staff there" (Farber, 1971, p. 23). A centralidade conferida ao governo metropolitano na gestão dos assuntos económicos angolanos suscitou a oposição das elites brancas locais. Desta atitude, ficou como exemplo a reforma do sistema de transferências, em 1971, medida tomada sem a consulta dos órgãos provinciais, o que provocou um grande descontentamento em Angola que era partilhado pelo António Garcia Castilho e Fernandes Vieira ${ }^{29}$. Os receios das elites face às consequências deste novo sistema tiveram tradução na quebra das importações, o aumento do custo de vida e ainda falta de alguns produtos básicos ${ }^{30}$.

Também as elites estavam atentas ao facto de que a participação do capital português era muito fraca, acusando "o governo português de proteger os grandes interesses económicos metropolitanos e estrangeiros presentes em Angola, em detrimento das necessidades, aspirações e interesses da população" (Pimenta, 2008, p. 331).

Como refere Fernando Tavares Pimenta, "o petróleo constituía precisamente um dos problemas principais que afetava o relacionamento político entre as elites brancas e o governo central" (Pimenta, 2008, p. 333). Em Angola também se verificavam dificuldades na transformação de grande parte das matérias-primas, onde a capacidade da única refinaria do território, sediada em Luanda, não se ajustava aos níveis de produção. As elites brancas apelavam à construção de uma refinaria em território angolano, existindo, em 1971, três locais possíveis para a sua construção: Lobito, Benguela, Baía Farta e Moçâmedes. Contudo, "crê-se que Benguela tenha sido excluída devido à falta de uma baía muito abrigada [...] Baía Farta haja sido posta de parte devido ao seu problema de falta de água [...] as entidades de Lobito e a empresa pretendente da instalação da refinaria tenha sido possível um entendimento [...] e assim é que parece chegar-se à conclusão de que estará reservada a Moçâmedes, dada as facilidade concedidas pelas entidades locais, a instalação de nova refinaria de petróleo"31. Contudo, o território angolano foi preterido por Sines, empreendimento industrial a que se fez menção anteriormente.

A questão petrolífera agravou, ainda mais, a relação entre as elites económicas de Angola e o governo central. É neste contexto que surge rumores sobre um possível plano secessionista, dado o apoio que o governo português conferia aos interesses externos em detrimento dos interesses locais. A possível repetição de uma independência brasileira sob o domínio das elites brancas, num modelo de minority rule, encontra eco na documentação rodesiana e sul-africana. Contudo, a documentação e a imprensa periódica consultada não deixam antever se as elites económicas estariam verdadeiramente empenhadas num projeto independentista e num corte de relação com Lisboa, embora figuras afetas ao regime como Franco Nogueira apontem em sentido contrário.

\section{5. “Uma arma chamada petróleo”32: Angola na crise de 1973}

A neutralidade europeia face ao conflito israelo-árabe, ocorrido entre 6 de outubro e 26 de Outubro de 1973, entre uma coligação de estados árabes liderados pelo Egipto e pela Síria contra Israel, colocou a diplomacia portuguesa numa situação constrangedora. $O$ isolamento internacional a que Portugal estava votado, devido a continuação da sua política colonial, levou a que a cedência a ultimato norte-americano para a utilização da base das Lajes, nos Açores, fosse a

${ }^{29}$ Boletim da Associação Industrial de Angola, ano XX, no 94/95, 1969, pp. 17-20.

30 Jornal de Benguela, no 4907, 18 de Junho de 1973, pp. 1-2.

31 Jornal de Benguela, n 4720, 30 de Outubro de 1971, p. 8.

32 Jornal de Benguela, no 4941, 15 de Outubro de 1973, p. 8. 
solução mais viável. Deste modo, a base das Lajes tornou-se na placa giratória da administração Nixon na gestão do conflito, com o envio de aviões, embora o presidente norte-americano afirma-se que "a política dos Estados Unidos é de apaziguamento" e baseada na defesa "de todos os países daquela região de manter a sua independência"33.

O choque petrolífero de 1973 teve repercussões na economia portuguesa, visto que a que diminuição do fornecimento foi "um golpe direto sobretudo à Europa dependente em 80 por cento do petróleo do Médio Oriente"34. Daniel Vieira Barbosa35 mostrava que se tinha instalado "no País uma situação decerto injustificada, mas que nem por isso deixa de ser preocupante. Demonstra-o as "bichas", longas e constantes, que teimosamente, persistentemente, se mantêm junto dos postos abastecedores; as lamentações e as críticas que, por vezes, em termos de desespero, se vão avolumando, tal qual bola de neve, de Norte ao Sul do País". As carências no abastecimento de combustíveis levavam, no dizer do antigo Ministro da Economia, a uma "psicose da falta" 36 , a que o governo deveria dar uma resposta cabal e concreta.

De modo a diluir os impactos da crise petrolífera, o governo decidiu tomar um conjunto de medidas, sob a coordenação da Direção-Geral das Combustíveis (DGC). Destarte, a DGC "[...] montou toda uma estrutura e organização adequada ao estudo, execução e acompanhamento das medidas necessárias à mais pronta resolução dos problemas" 37 , onde se contava a criação de um centro de despacho, uma comissão de estudo das dotações para a indústria, um grupo de trabalho do gás, um gabinete de emergência e um gabinete de estudos, tendo em vista a implementação e a análise de: [...]

[um] plano de racionamento por senhas, abastecimento de transportes aéreos, marítimos e rodoviários, plano de abastecimento a turistas, estudo da incidência na economia nacional da elevação do nível de preços dos produtos do petróleo, estudo e divulgação de medidas de economia de consumo de combustíveis, campanhas publicitárias ${ }^{38}$.

As consequências da crise petrolífera suscitam algumas propostas na Assembleia Nacional sobre a política energética seguida pelo Marcelismo, numa altura em que se debatia a estrutura do IV Plano de Fomento, que deveria ser colocado em prática entre 1974 e 1979. Assim, o deputado Armando Roboredo e Silva ${ }^{39}$, mostrando que as consequências da crise do petróleo eram ainda imprevisíveis na evolução da produção de energia, defendeu a criação de um Ministério da Energia 40 , um maior investimento governamental na energia hídrica e evitar o recurso à energia nuclear pois no "aspeto da poluição, além do receio de acidentes de que resultem problemas de contaminação, aliás pouco críveis, o óbice dos efluentes radioativos, que suponho constituir ainda a maior e mais difícil questão a resolver", defendendo ainda que "a eletricidade é a menos poluente das energias e daí a tendência para aumentar a sua produção"41.

\footnotetext{
33 Jornal de Benguela, no 4943, 22 de Outubro de 1973, p. 5.

34 Jornal de Benguela, no 4948, 8 de Novembro de 1973, p. 6.

35 Engenheiro civil de formação, lecionou na Faculdade de Engenharia da Universidade do Porto e no Instituto Superior Técnico, em Lisboa, tendo sido Bastonário da Ordem dos Engenheiros (1953). Entrou para o governo de Oliveira Salazar, como Ministro da Economia, cargo que exerceu entre 1947 e 1948, revelando-se como um dos próceres da industrialização portuguesa. Seria ainda deputado à Assembleia Nacional (1949-1974), Governador do Banco de Fomento Nacional (1965-1974) e Ministro da Indústria e Energia (1974).

36 Diário das Sessões da Assembleia Nacional, XI legislatura, no 8, 5 de Dezembro de 1973, pp. 90-91.

37 Petróleo: informação, no 8 (1973), p. 7.

38 Petróleo: informação, no 8 (1973), p. 7.

39 Oficial de Armada, era Professor do Instituto Superior Naval de Guerra. Foi Presidente da Câmara Municipal da Beira, em Moçambique (1936-1939), procurador à Câmara Corporativa e Deputado à Assembleia Nacional (1969-1974).
}

40 Em Março de 1974, foi criado o Ministério da Indústria e Energia, onde o titular da pasta, Daniel Vieira Barbosa, ocupou o cargo até à queda do regime, a 25 de Abril de 1974.

41 Diário das Sessões da Assembleia Nacional, XI legislatura, sessão legislativa no 1, no 6, 30 de Novembro de 1973, p. 55. 
As dificuldades no abastecimento petrolífero levam a que os trabalhos preparatórios do IV Plano de Fomento sofram algumas reavaliações. Fernando Carvalho Conceição 42 afirmava que o ambiente de incerteza sobre o consumo energético que se vivia deveria suscitar uma reflexão sobre a indústria petrolífera em Angola. 0 deputado enumerou como principais problemas: [...]

[...] a fraca participação do capital nacional, pois a maioria dos empreendimentos está baseada em capitais estrangeiros; a não transformação local de grande parte das matériasprimas [...] fraca cobertura geológica do território e reduzidos estudos de prospeção geral realizados ${ }^{43}$.

A atração de capitais nacionais na indústria extrativa angolana deveria ser uma das prioridades no IV Plano de Fomento. Mário Moreira defendia ainda que "o Governo terá de estar bem atento e não hesitar em tomar certas medidas coerentes para procurar conter aquela evolução dos custos que se revista de um efeito de propagação amplificada"44.

Nas vésperas do conflito entre Israel e os países árabes, em Abril de 1973 salientava-se que "nos sectores industriais onde os investimentos foram mais avultados a produção local ultrapassou consideravelmente as importações" 45 , onde se incluía a industria petrolífera e, nos finais de Agosto, as importações rondavam os 8.317.064 contos, enquanto as exportações eram de 10.860.324 contos, resultando um saldo positivo de 2.593 .260 contos 46 .

Mas no que concerne ao impacto do choque petrolífero de 1973 no caso de Angola, o fornecimento e os abastecimentos a Portugal ficam suficientemente afetados para que o governo recorresse à produção angolana para colmatar as suas carências. Rui Patrício, ministros dos Negócios Estrangeiros, mostrava que a iniciativa dos países da OPEP, "não afetará grandemente o País, uma vez que o Estado de Angola pode substituir no futuro, aquela fonte de importação"47. Dado o momento que se vivia, o governo português celebrou um acordo com a Gulf Oil Company, de modo a que, em caso de emergência, poderia usufruir do direito de prioridade nas importações aos preços correntes dos mercados internacionais.

A estrutura do mercado petrolífero foi igualmente afetada pela crise de 1973, uma vez que a obtenção de produtos refinados para o consumo interno da província tiveram de ser pagos a nível que excediam a referida estrutura, que se mostrava deficitária a nível do consumo, onde apenas $1 / 3$ do mercado angolano era abastecido pela produção local, vocacionada para a exportação. Além disso, as consequências do conflito repercutiram-se ainda no arranque de novas unidades industriais anexas à refinaria de Luanda, tendo sido inauguradas com relativo atraso.

A 13 de Novembro foram aumentados, pela primeira vez, os preços da gasolina e de gás butano, onde o governo provincial apelava aos consumidores a "a não abastecer antes que seja rigorosamente indispensável", mantendo os preços do gasóleo "enquanto for possível, apesar dos preços elevadíssimos que atingiram as importações"48. A difícil conjuntura internacional levou a algumas criticas por parte das elites angolanas, onde, nas palavras de Penteado dos Reis, "hoje, frente ao agudo problema, erguem-se correntes [no Portugal metropolitano] num quase patético venham a nós o petróleo de Angola" mostrando que dado o privilégio da província angolana ser o único território a sul do Equador com petróleo em condições comerciáveis, era a "oportunidade para que

\footnotetext{
42 Licenciado em Ciências Histórico-Filosóficas pela Universidade de Lisboa, era professor do ensino secundário, tendo sido reitor do Liceu de Guimarães. Foi deputado à Assembleia Nacional, pelo círculo de Braga (1969-1974). Depois do fim do Estado Novo, foi deputado à Assembleia da República (1985-1991) e governador civil de Braga (1994-1995).

43 Diário das Sessões da Assembleia Nacional, XI legislatura, sessão legislativa no 1, nº 11, 12 de Dezembro de 1973, p. 175.

${ }^{4}$ Diário das Sessões da Assembleia Nacional, XI legislatura, sessão legislativa no 1, no 11, 12 de Dezembro de 1973, p. 207.

45 Jornal de Benguela, no 4888, 12 de Abril de 1973, p. 1.

46 Jornal de Benguela, no 4951, 19 de Novembro de 1973, p. 1.

47 Jornal de Benguela, no 4949, 12 de Novembro de 1973, p. 4

48 Jornal de Benguela, no 4950, 15 de Novembro de 1973, p. 8.
} 
Angola [...] utilize da melhor forma o seu petróleo, tornando-o uma poderosíssima arma de desenvolvimento e progresso" 49 . Nestas afirmações, poder-se-á verificar que o pendor autonomista face ao poder central de Lisboa era uma realidade que, nas vésperas da queda do Estado Novo, ainda percorria as elites de Angola, reforçando as críticas ao sistema de transferências, onde "a derrogação ou a profunda modificação do atual regime cambial [...] envolve porém, a necessidade de acautelar o processo de industrialização, que a metrópole pretende abrandar"50.

Em suma, os efeitos do choque petrolífero fizeram-se sentir em Angola, embora de forma mais branda do que ocorreu no Portugal metropolitano, o que leva a concluir que os esforço governamental fora bem conseguido, tal como afirmava o ministro Cota Dias, dizendo que "tivemos em vista reduzir ao mínimo as "fendas" causadas na economia do país e só secundariamente nos preocupou o que é na realidade secundário" 51.

\section{Conclusão}

A indústria petrolífera ganhou, paulatinamente, um capital económico muito relevante, no quadro geral da economia angolana no ocaso do Estado Novo. A balança de pagamentos do governogeral de Angola conheceu saldos positivos após o início da exploração e prospeção de petróleo, sob o comando de empresas estrangeiras, embora algumas tivessem capital e participação do Estado português.

Todavia, o petróleo não deverá ser isolado, nem compreendido, exclusivamente, na sua esfera económica, conservando um capital político muito relevante, num contexto de constante procura e sustentação de formas de energia, a nível global. Deste modo, encontramos, durante o início da década de 1970, a utilização do petróleo como forma das elites brancas angolanas apresentarem a sua discordância com o governo metropolitano. A perceção da capacidade negocial que a indústria petrolífera encerrava mostrava às elites económicas as capacidades da economia local e qual deveria ser o seu futuro, onde a hipótese independentista terá sido colocada, embora sem efeitos práticos visíveis, mas agravando as já tensas relações entre as referidas elites, que encontravam na Associação Industrial de Angola, um dos seus bastiões, e o governo de Marcello Caetano.

Tendo em conta o choque petrolífero de 1973, consequência da Guerra do Yom Kippur, este teve repercussões na economia angolana, onde os seus efeitos não só se verificaram a nível exclusivamente económico, como também a nível político mostrando, mais uma vez às elites económicas, a subordinação do governo-geral ao governo metropolitano e as possíveis consequências da continuação deste elo político-governativo. Além disso, e como se poderá verificar nas páginas precedentes, a crise petrolífera de 1973 suscitou um interesse debate sobre a política energética seguida pelo governo marcelista, onde se exponham possíveis alternativas e um controlo governamental mais aguerrido no que concerne a esta área de atuação económica.

Assim, o estudo da indústria petrolífera revela-se crucial na compreensão das dinâmicas político-económicas que ocorriam entre a metrópole e as províncias ultramarinas no ocaso da ditadura.

\section{Referências}

\subsection{Fontes}

A Província de Angola: órgão dos interesses económicos da colónia.

Boletim da Associação Industrial de Angola.

Boletim-Geral do Ultramar.

49 Jornal de Benguela, no 4965, 6 de Dezembro de 1973, p.2 e p. 8.

50 Jornal de Benguela, no 4968, 20 de Dezembro de 1973, p. 2.

51 Jornal de Benguela, no 4971, 28 de Janeiro de 1974, p. 5.

(c) Labor \& Engenho, Campinas [SP] Brasil, v.11, n.4, p.507-519, out./dez. 2017. 
Jornal de Benguela

Petróleo: Informação

\subsection{Estudos}

A Indústria do Petróleo. Lisboa: Shell Portuguesa, 1955.

Antunes, J. F. (1990). O factor africano. Lisboa: Publicações Dom Quixote.

Clarence-Smith, G. (1990). O terceiro império português (1825-1975). Lisboa: Teorema.

Contrato entre a província de Angola e a Cabinda Gulf Oil Company (Cabgoc) para a concessão, em regime de exclusivo, de pesquisas e exploração de jazigos de hidrocarbonetos sólidos, líquidos e gasosos naquela província. Lisboa: Ministério do Ultramar, 1967.

Farber, S. (1972). Gulf and Angola. In Issue: A Journal of Opinion, 2 (3), pp. 21-31.

Glasgow, R. (1972). Recent Observations on the Developing Southern Strategy of Brazil, Portugal, and Africa. In. Issue: A Journal of Opinion, 2 (3), pp. 3-8.

Guerra, H. (1979). Angola: estrutura económica e classes sociais. Lisboa: Edições 70.

Oliveira, J. C. (1972). Servindo o futuro de Angola. Luanda: Edição do Autor.

Oliveira, J. E. (1985). A lógica da consolidação da economia de mercado em Angola, 1930-74. In Análise Social, 21 (85), pp. 83-110.

Martins, A. (2002). Sines 1971/2001 - 30 anos do projecto (vol. III, pp.354-373). In M. Heitor, J. M. B. de Brito, \& M. F. Rollo (coords.). Momentos de Inovação e Engenharia em Portugal no século XX. Lisboa: Publicações Dom Quixote.

Rollo, M. F. (2007). Marcelo Caetano: política económica e modernização. In Espacio, Tiempo y Forma, série 5, no 19, pp. 115-144.

Silva, F. G. da (2015). O(s) imaginário(s) da modernização: a evolução da indústria petrolífera portuguesa: das políticas industriais do Estado Novo às nacionalizações revolucionárias (pp. 179-186). In J. G. Irruzun \& J. Rubio-Mondéjar (coords.) Haciendo Historia Económica: nuevas investigaciones, nuevos investigadores. Granada: Editorial Universidad de Granada.

Souto, A. N. (2007). Caetano e o ocaso do "Império": administração e Guerra Colonial em Moçambique durante o Marcelismo (1968-1974). Porto: Edições Afrontamento.

Valério, N., \& Fontoura, M. P. (1994). A evolução económica de Angola durante o segundo período colonial: uma tentativa de síntese. In Análise Social, 29 (129), pp. 1193-1208.

Vaz, C. L. (2002). A engenharia na indústria petrolífera (vol. III, pp. 308-319). In M. Heitor, J. M. B. de Brito, \& M. F. Rollo (coords.). Momentos de Inovação e Engenharia em Portugal no século XX. Lisboa: Publicações Dom Quixote.

Veiga, I. (1999). 0 choque petrolífero de 1973. In História, ano XXI, no 18, pp. 50-57. 